\title{
Combustion Synthesis of Semiconductor Oxides and Evaluation of Adsorption and Photocatalysis Properties
}

Matheus Gomes Ferreira1, Henrique Cesar Abreu do Nascimento Telles Rodrigues ${ }^{1}$ Francisco Manoel dos Santos Garrido ${ }^{1, *}$, Marta Eloisa Medeiros ${ }^{1}$

\author{
Ferreira MG (D) https://orcid.org/000.0002-1446-1671 \\ Rodrigues HCANT (iD https: / / orcid.org/0000.0003-1353-1284 \\ Garrido FMS (D) https: / / orcid.org/0000-0001-7942-7549 \\ Medeiros ME (iD https://orcid.org/ 0000-0001-6445-3285
}

\section{How to cite}

Ferreira MG; Rodrigues HCANT; Garrido FMS; Medeiros ME (2019) Combustion synthesis of semiconductor oxides and evaluation of adsorption and photocatalysis properties. J Aerosp Technol Manag, 11, Special Edition: 54-57. https://doi. org/10.5028/jatm.etmq.22

\begin{abstract}
Improper disposal of effluent contaminated with organic dyes may cause environmental problems. In this context, the $\mathrm{ZnO}$ semiconductor and the $\mathrm{ZnO} / \mathrm{ZnFe}_{2} \mathrm{O}_{4}$ magnetic composite were prepared by the combustion method. The synthesized materials showed adsorption and photocatalysis properties for elimination of methylene blue dye from aqueous medium. About $88 \%$ of the methylene blue was eliminated by $\mathrm{ZnO}$ and $63 \%$ by the composite. In the photocatalysis process, a low cost visible light source was used. These materials can be regenerated by a photo-Fenton process. Moreover, the $\mathrm{ZnO} / \mathrm{ZnFe}_{2} \mathrm{O}_{4}$ composite can be separated from the reaction medium by a magnetic field.
\end{abstract}

KEYWORDS: Adsorption; Methylene blue; Magnetic composite; Semiconductor oxide; Photocatalysis; Combustion method.

\section{INTRODUCTION}

The textile industry is one of the most water-consuming sectors and, as a result, generates high volumes of effluents contaminated by synthetic organic dyes. When these effluents are not properly disposed, they cause serious environmental impact (Rani et al. 2017). In order to adapt effluents for disposal, the search for techniques that provide efficient treatment of these effluents is a constant. In this context, there has been a growth of studies of advanced oxidative processes, such as heterogeneous photocatalysis. This process has the activation of a semiconductor material from the incidence of light on it as its principle. Such materials have the ability to generate $\bullet \mathrm{OH}$ radicals by reducing dissolved oxygen molecules or by oxidizing adsorbed water molecules on the semiconductor surface. Such radicals are highly reactive and poorly selective, acting directly on the degradation of organic matter (Oliveira et al. 2013). Adsorption processes are also widely used since organic matter can be adsorbed onto the surface of the material, removing it from the aqueous medium. For adsorption, activated carbon is widely used due to its high surface area, as also some nanostructured iron oxides and nanostructured $\mathrm{ZnO}$ (Rani et al. 2017). Due to their semiconductor and piezoelectric properties, $\mathrm{ZnO}$ has also been used in the preparation of optoelectronic devices that have application in the aerospace sector (Fernandes et al. 2016; Safyanu et al. 2019) This work aims the synthesis of $\mathrm{ZnO}$ and the magnetic composite $\mathrm{ZnO} / \mathrm{ZnFe} \mathrm{O}_{4}$ by the combustion method using starch as fuel (Argolo et al. 2019; Siqueira Junior et al. 2019). The obtained materials were evaluated in the adsorption and photodegradation processes of the methylene blue dye, using a low cost commercial visible light source for photocatalytic evaluation.

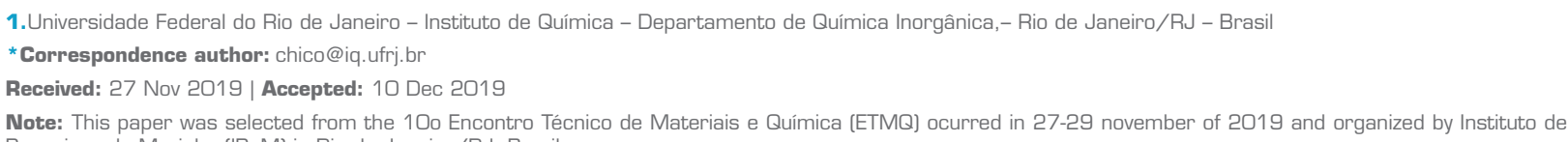




\section{MATERIALS AND METHODS}

In the synthesis of the $\mathrm{ZnO} / \mathrm{ZnFe}_{2} \mathrm{O}_{4}$ composite, $0.004 \mathrm{~mol}$ of $\mathrm{ZnCO}_{3}$ was solubilized in concentrated $\mathrm{HNO}_{3}(0.6 \mathrm{~mL})$, then $25 \mathrm{~mL}$ of distilled water, $0.004 \mathrm{~mol}$ of $\mathrm{Fe}\left(\mathrm{NO}_{3}\right)_{3} \cdot 9 \mathrm{H}_{2} \mathrm{O}$ and $0.0123 \mathrm{~mol}$ of starch were added. The $\mathrm{pH}$ of the medium was then adjusted to 6 using $1 \mathrm{~mol} / \mathrm{L}$ of $\mathrm{NH}_{4} \mathrm{OH}$ solution. The system was submitted to a glycerin bath for $23 \mathrm{~h}$ at $65^{\circ} \mathrm{C}$. After obtaining the xerogel, it was calcined in the muffle furnace for $1 \mathrm{~h}$ at $200^{\circ} \mathrm{C}$. The solid was then macerated and then subjected to a new muffle heating process for $1 \mathrm{~h}$ at $300^{\circ} \mathrm{C}$. The synthesis of $\mathrm{ZnO}$ differs only by not adding iron salt. The products obtained were black and the $\mathrm{ZnO} / \mathrm{ZnFe}_{2} \mathrm{O}_{4}$ composite presents magnetization when subjected to magnetic field. X-Ray diffraction (XRD) was obtained on a Rigaku ( $\mathrm{Cu} \mathrm{K}_{\alpha}$ radiation) in the angular range from $10^{\circ}$ to $80^{\circ}(2 \theta)$. The crystalline phases present in the samples were identified by comparison to available crystallographic data in the Inorganic Crystal Structure Database (ICSD). The X-ray powder diffraction data was analyzed by ERACEL software.To evaluate the adsorption properties of the synthesized materials, $25.0 \mathrm{~mL}$ of a $24 \mathrm{mg} / \mathrm{L}$ methylene blue (MB) solution and $25 \mathrm{mg}$ of the synthesized material were used. The material/solution system was kept in a dark environment for $4 \mathrm{~h}$ in order to achieve the equilibrium adsorption/desorption and, after this period, a $2 \mathrm{~mL}$ aliquot of the solution (T1) was taken. To evaluate the photocatalytic activity, the system was transferred to a petri dish surrounded by aluminum foil and irradiated by a led lamp $(15 \mathrm{~W})$. A distance of $7 \mathrm{~cm}$ was maintained between the lamp and the surface of the solution. A new aliquot was collected after $2 \mathrm{~h}$ of exposure to the light source (T2). T1 and T2 aliquots and the standard solution were analyzed by the UV-Visible absorption spectroscopy technique. UV-Vis spectra were obtained on Shimmadzu UV-2600 spectrophotometer between $200-900 \mathrm{~nm}$. In both the adsorption and photocatalysis processes magnetic stirring was used. Each process was performed in duplicate. To regenerate the adsorption capacity of the materials, the following photon-Fenton procedure was performed: With the addition of $\mathrm{H}_{2} \mathrm{SO}_{4}(1.0 \mathrm{~mol} / \mathrm{L})$, the $\mathrm{pH}$ of the supernatant solution was adjusted to 4 and then $10 \mathrm{ml}$ of $\mathrm{H}_{2} \mathrm{O}_{2}(0.17 \mathrm{~mol} / \mathrm{L})$ was added; thereafter the dispersion was kept under stirring and irradiated by the $15 \mathrm{~W}$ led lamp for $2 \mathrm{~h}$. The solids were isolated by centrifugation $(\mathrm{ZnO})$ or by decantation under the action of a magnetic field $\left(\mathrm{ZnO} / \mathrm{ZnFe}_{2} \mathrm{O}_{4}\right.$ composite).

\section{RESULTS AND DISCUSSION}

The crystal phases of samples were studied by XRD (Fig. 1); for the ZnO sample, the observed peaks were identified as zinc oxide wurtzite phase structure, indexed by JCPDS file 36-145. The magnetic composite $\left(\mathrm{ZnO} / \mathrm{ZnFe}_{2} \mathrm{O}_{4}\right)$ is comprised of $\mathrm{ZnO}$ wurtzite phase and zinc ferrite cubic phase, indexed by JCPDS file 74-2399. The crystallographic date of these phases (summarized in Table 1) is compatible with the literature (Chen et al. 2017). Both materials present their crystalline phases with nanometric crystallite sizes (Table 1), according to the Scherrer equation (Siqueira Junior et al. 2019).

The adsorption and photocatalysis studies are presented in Figs. 2 and 3. The UV-Vis spectra shows a large decrease in the absorption intensity of $\mathrm{MB}$ bands after the incubation period (T1 samples) indicating the adsorption of MB molecules on the surface of both tested solids. The higher $\mathrm{MB}$ adsorption for the $\mathrm{ZnO}$ sample can be explained by the smaller $\mathrm{ZnO}$ phase crystallite

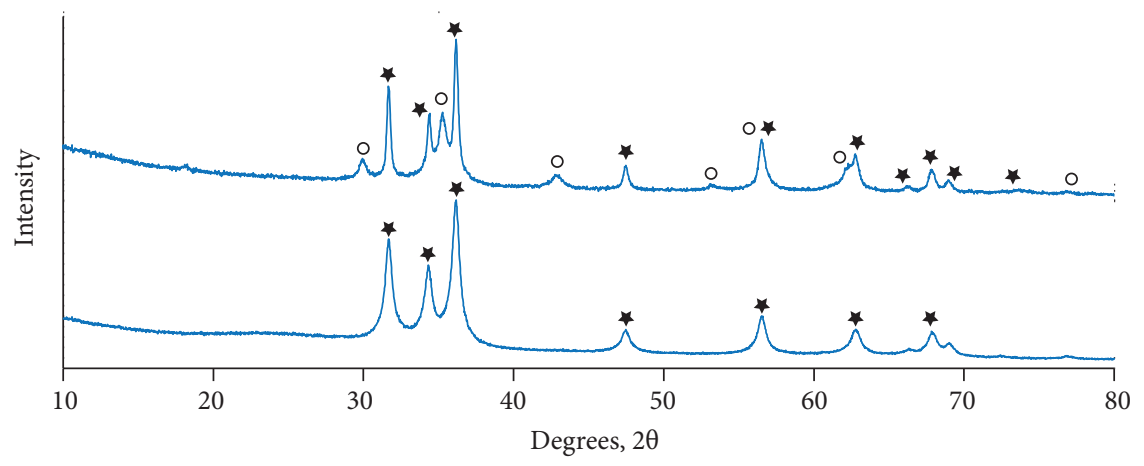

* $\mathrm{ZnO}$

$\circ \mathrm{ZnFe}_{2} \mathrm{O}_{4}$

Figure 1. $\mathrm{XRD}$ patterns for: (a) $\mathrm{ZnO} / \mathrm{ZnFe}_{2} \mathrm{O}_{4}$ and (b) $\mathrm{ZnO}$. 
size of this sample (Table 1). The decrease in UV-Vis absorption intensity can still be observed when the system was exposed to visible light irradiation (T2 samples) indicating that the remaining dye was undergoing the photocatalytic degradation process (Chen et al. 2017). After photocatalysis for $120 \mathrm{~min}$ (T2), the materials showed the following MB elimination capacities $\left(\mathrm{mg}_{\mathrm{MB}} / \mathrm{g}_{\text {adsorbent }}\right): \mathrm{ZnO}=21.1 \mathrm{mg} ; \mathrm{ZnO} / \mathrm{ZnFe}_{2} \mathrm{O}_{4}$ composite $=15.1 \mathrm{mg}$. These results are similar or higher to those described in the literature for similar materials - $16.6 \mathrm{mg}$ and $9.9 \mathrm{mg}$, respectively observed by Rani et al. (2017) and Chen et al. (2017).

It should be noted that both materials can be regenerate by a photon-Fenton methodology after recovery and reused. After regeneration, the materials maintained their MB adsorption capacity, and the following values were observed $\left(\mathrm{mg}_{\mathrm{MB}} / \mathrm{g}_{\text {adsorbent }}\right)$ : $\mathrm{ZnO}=24.0$ and $23.5 \mathrm{mg} ; \mathrm{ZnO} / \mathrm{ZnFe}_{2} \mathrm{O}_{4}$ composite $=23.8$ and $21.1 \mathrm{mg}$, respectively for the first and second regeneration. It was found that $\mathrm{ZnO} / \mathrm{ZnFe}_{2} \mathrm{O}_{4}$ continued to have magnetic activity after the regeneration, which is an important point in the process of separating the composite from the reaction medium.

Table 1. XRD data of synthesized samples analyzed by ERACEL software.

\begin{tabular}{|c|c|c|c|}
\hline Sample & $\mathrm{ZnO}$ & \multicolumn{2}{|c|}{$\mathrm{ZnO} / \mathrm{ZnFe}_{2} \mathrm{O}_{4}$} \\
\hline Phase & $\mathrm{ZnO}$ & $\mathrm{ZnO}$ & Zinc Ferrite \\
\hline$a=b[\AA]$ & 3.253 & 3.261 & 8.482 \\
\hline$c(\AA)]$ & 5.214 & 5.212 & 8.482 \\
\hline$V(\AA ̊)]$ & 47.673 & 48.004 & 610.112 \\
\hline $\begin{array}{c}\text { D [nm] } \\
\text { Crystallite size }\end{array}$ & 13.5 & 23.9 & 14.0 \\
\hline
\end{tabular}

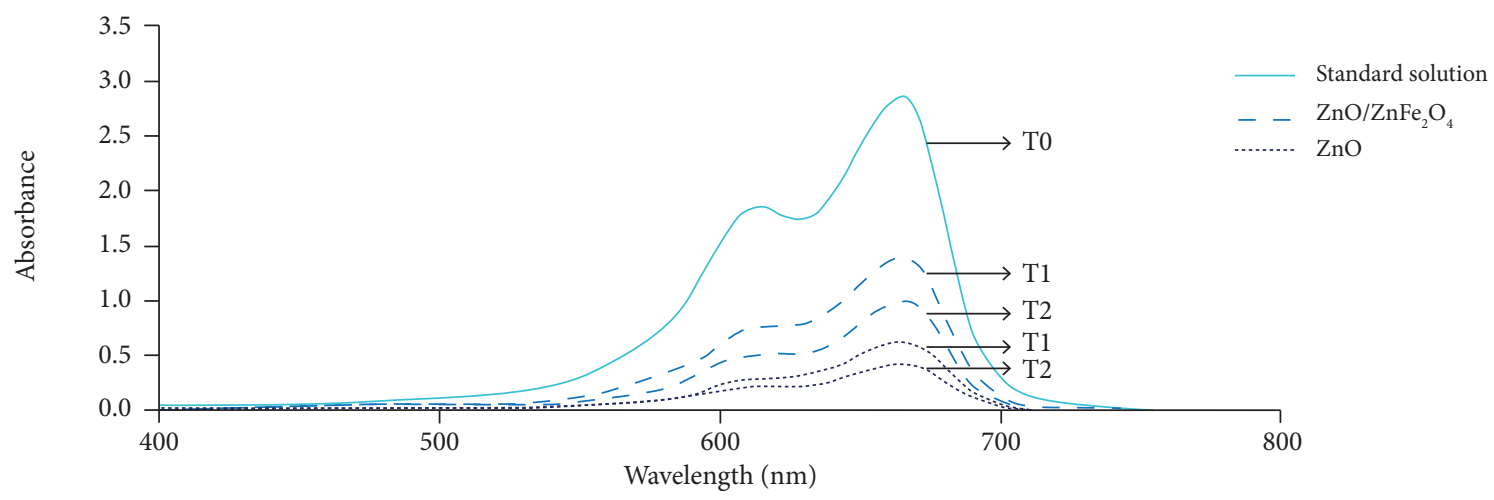

Figure 2. UV-Vis spectra of the supernatant solution MB, where TO = standard MB solution, T1 = aliquot taken after $4 \mathrm{~h}$ in adsorption equilibrium and T2 = aliquot taken after $2 \mathrm{~h}$ under light for synthesized materials

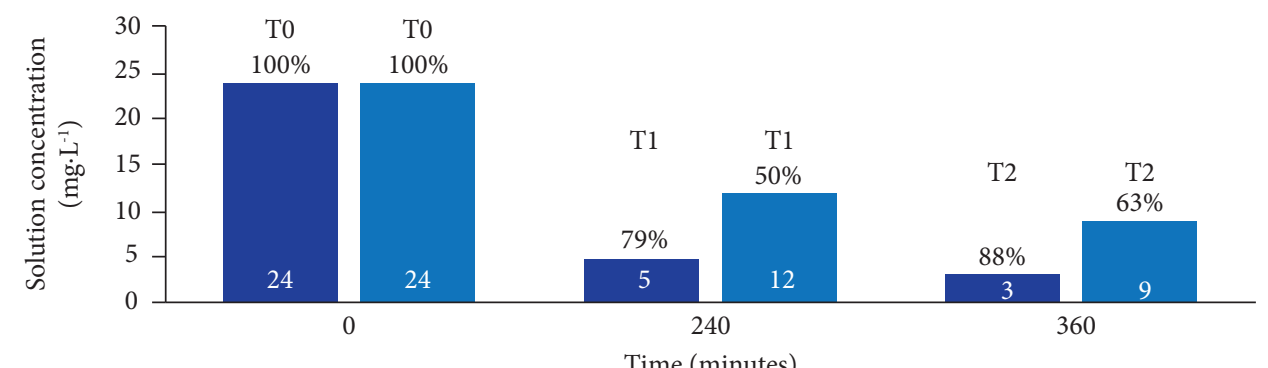

Figure 3.Solution concentration MB versus exposure time, where: 0 = standard MB solution; 240 = adsorption/desorption process and 360 = photocatalysis processes for synthesized materials. 


\section{CONCLUSION}

The use of the combustion method allowed to obtain $\mathrm{ZnO}$ and $\mathrm{ZnO} / \mathrm{ZnFe}_{2} \mathrm{O}_{4}$ composite that has magnetic property. Both materials showed potential to be applied in the methylene blue dye adsorption and photodegradation processes, using a low cost visible light source. The synthesis method was reproducible, simple and versatile. These adsorbents can be regenerated using a simple methodology.

\section{ACKNOWLEDGMENTS}

The authors would like to thank XRD Multi-Users and DQI Instrumental Analysis/UFRJ for their scientific support.

\section{FUNDING}

Conselho Nacional de Desenvolvimento Científico e Tecnológico [http://doi.org/10.13039/501100003593]

Grant 577904/2008-6

Coordenação de Aperfeiçoamento de Pessoal de Nível Superior [http://doi.org/10.13039/501100002322]

\section{AUTHORS' CONTRIBUTION}

Conceptualization, Garrido FMS and Medeiros ME; Methodology, Ferreira MG and Rodrigues HCANT; Investigation, Ferreira, MG and Rodrigues, HCANT; Writing - First version, Ferreira, MG; Writing - Review \& Editing, Garrido FMS and Medeiros ME; Supervision, Garrido FMS and Medeiros ME.

\section{REFERENCES}

Argolo MISA, Silva LS, Siqueira Junior JM, Miranda FS, Medeiros ME, Garrido FMS (2019) Structural and optical properties of Ni/NiO composites synthesized by ecofriendly self-propagation synthesis (SHS): Effects of NH4OH addition. Ceram Int 45(17):21640-21646. https: / / doi.org/10.1016/j.ceramint.2019.07.161

Chen M, Liu D, Deng Y, Fu W, Zou H, Liang F (2017) Tailoring the porosity of ZnO/ZnFe204 composites for photocatalytic applications. Ceram Int 43(17):16027-16031. https://doi.org/10.1016/j.ceramint.2017.08.148

Fernandes FW, Paiva VFG, Thim GT (2016) Energetic and electronic properties in a multilayered ZnO graphene-like nanostructure. Mat Res 19(3):497-504. https://doi.org/10.1590/1980-5373-MR-2015-0432

Oliveira LCA, Fabris JD, Pereira MC (2013) Óxidos de ferro e suas aplicações em processos catalíticos: uma revisão. Quím Nova 36(1):123130. https://doi.org/10.1590/S0100-40422013000100022

Rani GJ, Rajan MAJ, Kumar GG (2017) Reduced graphene oxide/ZnFe204 nanocomposite as an efficient catalyst for the photocatalytic degradation of methylene blue dye. Research on Chemical Intermediates 43(4):2669-2690. https://doi.org/10.1007/s11164-016-2788-0

Safyanu BD, Abdullah MN, Omar Z (2019) Review of power device for solar-powered aircraft applications. J Aerosp Technol Manag 11:1-16. https://doi.org/10.5028/jatm.v11.1077

Siqueira Junior JM, Machado CT, Quattrociocchi DSG, Garrido FMS, Costa LM, Ponzio EA, Ferreira GB, Resende JALC (2019) Experimental and theoretical study of LiMn204 synthesized by the solution combustion method using corn starch as fuel. J Braz Chem Soc 31:1-13. https:// doi.org/10.21577/0103-5053.20190192 